\title{
Temptation in Purchasing Decision: A Quasi Experiment to Validate the Set Betweenness Axiom
}

\author{
Reddy Sai Shiva Jayanth, Kausik Gangopadhyay \\ Indian Institute of Management Kozhikode, IIMK Campus, Calicut, India \\ Email: reddys10fpm@iimk.ac.in, kausik@iimk.ac.in
}

How to cite this paper: Jayanth, R.S.S. and Gangopadhyay, K. (2018) Temptation in Purchasing Decision: A Quasi Experiment to Validate the Set Betweenness Axiom. Theoretical Economics Letters, 8, 1709-1720. https://doi.org/10.4236/tel.2018.810111

Received: March 29, 2018

Accepted: June 16, 2018

Published: June 19, 2018

Copyright (c) 2018 by authors and Scientific Research Publishing Inc. This work is licensed under the Creative Commons Attribution International License (CC BY 4.0).

http://creativecommons.org/licenses/by/4.0/

\section{(c) (i) Open Access}

\begin{abstract}
We examined the Set Betweenness axiom, the most crucial assumption in the literature studying Temptation and Self-control starting with the seminal work by Gul and Pesendorfer [1]. This axiom states that presence of a tempting alternative creates a self-control problem for the decision maker who prefers a menu that does not include the tempting alternative over a menu that does. We identified reduced price as a tempting alternative and conducted a quasi-experiment on 288 respondents. The respondents expressed their preference between menus and alternatives that contain a tempting good at a reduced price and/or that good at a non-reduced price. We chose ice cream and shirt as two different choices for goods. Our results demonstrate that that choice that is consistent with Set Betweenness Axiom is the most observed choice. Moreover, people with more familial wealth may have higher preference for commitment.
\end{abstract}

\section{Keywords}

Temptation, Self Control, Set Betweenness, Commitment Ranking, Quasi Experiment

\section{Introduction}

Temptation and self-control is modelled by Gul \& Pesendorfer [1]. The critical assumption of their paper is the Set Betweenness axiom that says that mere presence of the tempting alternative in a menu creates a self-control problem for the decision maker (henceforth, DM) and hence makes the menu no better than the menu without it. This is a critical violation of the axiom that more alternative as choice is always better preferable to a decision-maker. 
We carried out a quasi-experiment to verify the Set Betweenness axiom. We identified reduced price as a source of temptation to the potential buyers, from our survey. We described a scenario and asked respondents of their potential choice on the face of this temptation. More elaborately, we motivated survey participants to imagine a reality in which they were facing pecuniary problem and pressed to not buy any of the good, in question. The idea of reduced price as a source of temptation originates from there.

They were offered choices to pick between three menus: One, the menu without reduced price; two, the menu with and without reduced price; and, three, the menu with only reduced price. A decision maker without any temptation problem shall pick up either the second or the third option. However, a decision maker with temptation will prefer the first option. We conducted our experiment with two goods-ice cream and shirt-whose purchase is considered a constant source of temptation among the target population of our survey.

Our empirical analysis shows that approximately $44 \%$ of the respondents chose the first menu. The respondent's response demonstrated quite strong evidence in favor of Gul \& Pesendorfer [1]. Even though, Gul \& Pesendorfer [1] is a seminal work, the empirical verification of this work is relatively less. Therefore, our work contributes to the support of this theory.

Temptation has huge implications on the typical linkage between market and consumer welfare. Market is portrayed as a choice-enabling force. However, more choice may mean less welfare on account of the Set Betweenness axiom. Therefore, consumers may prefer to not exercise their prerogative of choice and may want to limit their choice set. The instrument to limit choice is typically called a temptation (proof) asset. Our study may suggest possible promotion for temptation (proof) assets.

The rest of the sections are organized as follows. Section 2 reviews the literature on the importance of the work, Gul \& Pesendorfer model, and some empirical studies related to it. Section 3 describes the Economic framework of Gul \& Pesendorfer model and also connects our experiment to this framework. Section 4 highlights our results to demonstrate their essence to Gul \& Pesendorfer model. Section 5 concludes our study.

\section{Literature Review}

Gul and Pesendorfer (henceforth GP) formalized the concept of temptation to model human behavior. The GP theory assumes that a DM may be better off if some particularly tempting option were not available to her at the first place, even if she does not choose that option. As a consequence, she may be willing to pay in advance to eliminate that option, or in other words, she may have a preference for commitment. For instance, we may want to purchase consumption goods today, but may not want our future selves to purchase consumption goods.

[1] [2] captured the feature that only immediate consumption tempts the DM 
in any period, even though ex-ante choice between menus is not subject to temptation. Noor generalized the GP framework and considered the implications of temptations by future consumption [3]. This generalized model explains why individuals in spite of being aware of their self-control issues, do not take advantage of commitment opportunities. While original GP model considers only preference between alternatives, Noor considers preferences between menus containing those alternatives [4]. All these works assume the Set Betweenness axiom, even though their actual modelling may differ.

Being closely related to the psychology discipline, the constructs of temptation and self-control were widely studied in the context of ego depletion, goal attainment etc. Milyavskaya \& Inzlicht [5] found that people feel depleted when they face temptations. Temptation also mediated links between depletion and goal attainment, such that those who were tempted more, felt more depleted and hence were less successful in attaining their goals.

Due to its appealing framework, the GP model has been applied to study host of real life phenomenon. Hiraguchi [6] for instance, used this model in monetary economy scenario to analyze how individuals are tempted to spend all their money in current period than the future period. He found that a positive nominal interest rate increase would lead to increase in welfare because it reduces real money balance and hence makes temptation less attractive. Woźny [7] studied the problem of temptation in a principal-agent set-up, in which the principal exhibits problems of self-control and showed that in presence of strong self-control problems, moral hazard cost can be reduced. Further, the GP model has been used to understand how linear tax schedules can help improve individual's welfare in presence of temptation and self-control [8].

Empirical studies to validate the GP model are comparatively lesser. Houser, Schunk, Winter, \& Xiao [9] obtained empirical evidence from controlled environment. They paid the subjects to pursue a distasteful task but were tempted to give up their wage for counting and surfing the internet. The subjects were also provided with the option of committing to counting task by eliminating the option to surf the internet. They concluded that substantial fraction of subjects incurs pecuniary costs to eliminate choice in favor of commitment.

Hicken et al. [10] conducted a randomized controlled trial of an anti-vote selling intervention in Philippines. They randomly assigned individuals participants (voters) to treatment which would elicit them in making certain promises intending to reduce the vote selling. Their model and empirical results suggest that simple promise of not taking money from candidates, which acts as a commitment device, can reduce vote selling.

Apart from the experimental studies, there have been other empirical studies.

Huang, Liu, \& Zhu [11] intended to estimate the quantitative strength of the GP model using household level data from consumer expenditure survey. They exploited an implication of GP theory that more tempted individuals should be more likely to hold commitment assets. In their regression equation they studied 
the relation between wealth consumption ratio and households participation in savings investments like IRA (commitment devices). They found that temptation parameter in households holding IRA's is twice as large as those who were not.

Ameriks, Caplin, Leahy, \& Tyler [12] developed a survey instrument to study self-control problems that correlates with wealth measures. They collected responses related to self-control problems of participants in a hypothetical choice scenario. A simple regression analysis between self-control problems and wealth accumulation showed a significant negative relation. Meaning, an over consumer (person with high self-control problems) accumulates lesser wealth than one with no self-control problems. They further found that self-control problems have higher impact on liquid assets than on illiquid assets. Also, their results show that older people have lesser self-control problems than the younger ones. So in essence, the literature on wealth says that higher the temptation, higher would be the savings. On the other hand, higher self-control problems lead to lower wealth accumulation.

No studies in the past were conducted which particularly tried validating the Set Betweenness axiom as well as price induced temptation. The studies on temptation and self-control problems in the context of changing wealth levels, has also been very scarce, as depicted above.

\section{Economic Framework and Design of the Quasi-Experiment}

\subsection{The GP Model: A Particular Case}

The idea of temptation and self-control was formalized by defining the preferences over consumption sets. In essence, in the initial period there is a choice of menu, and in each subsequent period, there is a choice from a menu. Let us consider a situation in which an individual has to choose between two alternatives, $\{x, y\}$ and in choosing among these two absolute menus (i.e. a singleton sets of these two alternatives, $\{x\}$ and $\{y\})$ she would choose $\{x\}$ over $\{y\}$ as the individual ranks $x$ over $y$.

Now consider another situation where the menu is expanded to include y too, which is basically an inferior choice and may distort the utility the individual gets. GP model captures this preference through "Set Betweenness axiom" as $\{x\}$ being preferred to $\{x, y\}$. A standard individual should be indifferent between $\{x\}$ and $\{x, y\}$ as she judges it by the best elements of the set and both these sets have $\{x\}$ in them. However the DM in this case might suffer from temptation and may either end up succumbing to temptation or exert self-control to resist the temptation. In both the cases, she is worse off as compared to the case where there is no tempting alternative, making $\{x, y\}$ lesser preferable to $\{x\}$. This is allowed by Set Betweenness.

Also let us assume that alternate $y$ is more tempting than the alternative $x$, because when faced with the presence of $y$ in the menu, the individual may either 
succumb to the temptation and consume y or impose self-control and still consume $\mathrm{x}$, albeit with a lower utility than when $\mathrm{x}$ was the only option in menu. Therefore, this can be defined as preference of $\{x, y\}$ over $\{y\}$. Self-control decisions thus exhibit the following relation among the alternative menus $\{x\}\{x, y\}$ $\{y\}$. So, it is understood that an individual takes into account her commitment to an alternative as well as her temptation while making a decision. Hence effectively, that alternative is selected which maximises the sum of commitment and temptation utilities. The relevant utility function for the DM in period 1 is given by the following equation, termed as preference for commitment in the GP model.

$$
W(A)=\max _{x \in A}\{U(x)+V(x)\}-\max _{y \in A} V(y)
$$

where $W$ is the linear utility function of the decision maker. $A$ is the set of alternatives (also called a menu) she has in the period 1 whereas $x \in A$ is the particular alternative chosen in period 2. Both $U$ and $V$ are utility functions over alternatives. $U$ represents the Commitment ranking, i.e. the decision maker's ranking in the absence of temptation. $\mathrm{V}$ is the temptation ranking.

In the period 2, the actual behavior that a person exhibits involves maximizing $U(x)+V(x)$. Given the already selected menu, A, in period 1, the period 2 preferences are represented by the following equation

$$
W^{*}(A, x)=U(x)+V(x)-\max _{y \in A} V(y)
$$

where $W^{\star}$ is the linear utility function of the DM when faced with alternative set A and chooses alternative $x$. So in effect, in the initial period the DM chooses between the menus, whereas in the subsequent period she chooses between various alternatives in a particular menu.

$\operatorname{Max}_{y \in A} v(y)-v(x)$ is the cost that an individual incurs when trying to avoid a tempting alternative, hence termed as cost of self-control. By definition, we know that $\operatorname{Max}_{y \in A} v(y)-v(x)$ is always positive and hence this cost always goes into reducing the utility an individual obtains in presence of a tempting alternative.

\subsection{Projection of Our Experiment to GP Model}

\subsubsection{Description of Our Experiment}

In our survey, we designed a questionnaire to find out the temptation and self-control behavior among post graduate students in a top-ranked Indian business school. As for the choice of a tempting good, ice cream is generally chosen in the literature [13]. However, one may argue that temptation through a food based choice may have limited appeal. Purchase of garment is a common temptation which induces self-control problem among people. Twitchell, [14] said through the phrase "Today I will not buy another garment with a Ralph Lauren logo, even if it's at a factory outlet store." Shirt was a common garment for the target population of our experiment irrespective of sex and socio-economic background. Therefore, we chose shirt as another tempting good. 
We demonstrated that the survey respondents validated these assumptions of ours.

In case of ice cream, we framed the situation by mentioning in our questionnaire that the respondent has made a new year resolution to not take ice cream in view of his/her health. In case of shirt, we mentioned in the questionnaire that the respondents had enough shirts in their wardrobe and they made up their mind not to buy new shirts for another year. By asking the respondents to make this thought experiment, we emphasized to them that the product in question (ice cream or shirt) was actually undesirable. Therefore, commitment utility wise, the option of being able to buy another shirt is worse than not having that option. Nevertheless, a shirt has temptation utility for a respondent.

We assume that the respondents were tempted by a lower price to buy a product of their desire. Therefore, we introduced price to induce a greater degree of temptation towards the lesser priced product in our survey. We have validated this assumption again in the survey. An individual in our survey may have two distinct alternatives, $\mathrm{x}$ and $\mathrm{y}$, where $\mathrm{x}$ represents the option of buying the product at a higher price which is INR 200 (about 3 US dollars) in case of ice cream, and INR 1000 (about 16 US dollars) in case of shirt. Similarly, y represents the option of buying the product at a reduced price which is INR 100 (about 1.5 US dollars) in case of ice cream, and INR 500 (about 8 US dollars) in case of shirt. Our framed prices reflect the common prices prevalent in the city, the reduction in price was drastic to induce temptation.

We stated three menus for the surveyed individual in period 1 . We ask the respondents to choose one of the menus:

Menu $\mathbf{P}=\{x\}$ : Availability of the product at a higher price, say shirt at INR 1,000 .

Menu $Q=\{x, y\}$ : A combination of availability of the product at both higher and lower prices, say INR 1000 \& INR 500 for shirt.

Menu $\mathbf{R}=\{y\}$ : Availability of the product at a lower price, say shirt at INR 500.

We could observe the individual's preference for commitment as well as their exercise of self-control based on the choice of the individual as elaborated below. To judge a respondent's choice in period 2, we enquired the respondent's choice when she had the option to visit either Store $X$ with option $X$ (where the shirt is available only at INR 1000) or Store $Y$ with option y (where the shirt is available only at INR 500):

\subsubsection{GP Choice, Internally Consistent and Inconsistent Choice}

With the objective of not buying the shirt, the DM would prefer $\mathrm{x}$ than $\mathrm{y}$ because that would help her easily resist the temptation and not buy the shirt. Whereas $y$ instead $\mathrm{x}$ of may induce temptation due to presence of discount. Hence commitment ranking of the alternatives $\mathrm{x}$ and y would be $U(x)>U(y)$, and temptation ranking would be $V(y)>V(x)$.

Scenario 1: Menu containing only the high price option: We use the nota- 
tion $W^{\star}(\{x\}, x)$ to imply that the respondent has Menu $\mathrm{P}$ and she can only choose $\mathrm{x}$. In this case, the resultant utility that would accrue would be

$$
W(P)=W^{*}(x, x)=U(x)+V(x)-V(x)=U(x) .
$$

In this case the respondent should ideally choose to visit store $X$ when offered a choice between store $X$ and store $Y$ because he exhibits preference for commitment in period 1 . Hence $(P, X)$ is the selection that supports GP model-where $P$ is the choice among menus and $X$ is the choice among alternatives-whereas $(P, Y)$ goes against not only the GP model but also is internally inconsistent. A DM who chooses $P$ to positively limit her temptation will never go for $Y$ that is succumbing to temptation.

Scenario 2: Menu containing only the low price option: On the other hand, the individual is provided with a single option of visiting store $\mathrm{Y}$ alone. In this case, the resultant utility that would accrue would be

$$
W(R)=W^{*}(y, y)=U(y)+V(y)-V(y)=U(y)
$$

A GP respondent can, no way, choose $R$ over $P$ in period 1 . Therefore, this is the case that contradicts the GP mode. In this case, $(R, Y)$ is the time-consistent behavior, unlike the other case $(R, X)$.

Scenario 3: Menu containing both options: We then consider the case where individual chose menu $Q$ in period 1. If she selects $X$ in period 2, the resultant utility that would accrue would be

$$
W(Q)=W^{*}(\{x, y\}, x)=U(x)+V(x)-V(y)
$$

If she selects $\mathrm{Y}$ in period 2, the resultant utility that would accrue would be

$$
W(Q)=W^{*}(\{x, y\}, y): U(y)+V(y)-V(y)=U(y)
$$

The selection of $Q$ in period 1 is in violation of GP model. As the individual obtains lesser utility by selecting menu $Q$ over Menu $P$, there is no way a GP agent selects Menu $Q$. However, in period 2, when presented with a choice among the alternatives, if the individual exercises self-control, her selection would be $(Q, X)$ on the other hand, if she succumbs to temptation her selection would be $(Q, Y)$ (Table 1$)$.

Table 1. Summary of consistency of pairwise selection among menus and alternatives.

\begin{tabular}{cccc}
\hline $\begin{array}{c}\text { Selection from menus } \\
\text { in period 1 }\end{array}$ & $\begin{array}{c}\text { Selection from alternatives } \\
\text { in period 2 }\end{array}$ & $\begin{array}{c}\text { Ideal selection as } \\
\text { per GP model? }\end{array}$ & Internal Consistency \\
\hline$P$ & $X$ & Yes & Consistent \\
$Q$ & $X$ & No & Inconsistent \\
& $Y$ & No & Consistent \\
$R$ & $X$ & No & Consistent \\
$Y$ & No & Inconsistent \\
\hline
\end{tabular}




\section{Results and Discussion}

\subsection{Validity of Assumption from the Survey}

Our survey was conducted among the Management students of a reputed Indian institution almost exclusively all of whom comes from the age group $22-26$. Total sample size was 288 , including a few missing observations. We considered four wealth brackets out of which the large majority of $68.40 \%$ belonged to the lowest wealth bracket of having familial asset of INR 2 million (about 30,700 US dollars) or less. $20.40 \%$ of the respondents declared having a family asset between INR 2 million and 5 million (about 77,000 US dollars). 7.20\% indicated a family wealth between INR 5 million and 10 million (about 154,000 US dollars). Only $4.0 \%$ of the respondents belonged to the highest wealth bracket of having family assets of more than INR 10 million.

The respondents were asked to give themselves a score from $0-100$, which would indicate how successful they were in controlling his/her temptations to purchase a product. An average score of 61 was obtained indicating that the respondents were confident and believed that they were good enough in controlling their temptations. Further, we asked, irrespective of whether a product is bought or not, would a lower price cause temptation in the respondents. Almost $84 \%$ of the respondents (See Figure 1) agreed that lower price did induce certain degree of temptation in them to purchase the product, which was crucial to verification of our key assumption in setting up the quasi-experiment.

\subsection{Baseline Results}

We asked the respondents to indicate their preference for the menus $P, Q$ or $R$. The respondents' preferences are tabulated in Table 2. A GP agent will choose $\mathrm{P}$ as the first preference, $Q$ as the second preference and $\mathrm{R}$ as the third preference. For both ice cream and shirt, the most popular preference is identical to the GP agent's choice. This is a crucial evidence in favor of Set Betweenness axiom.

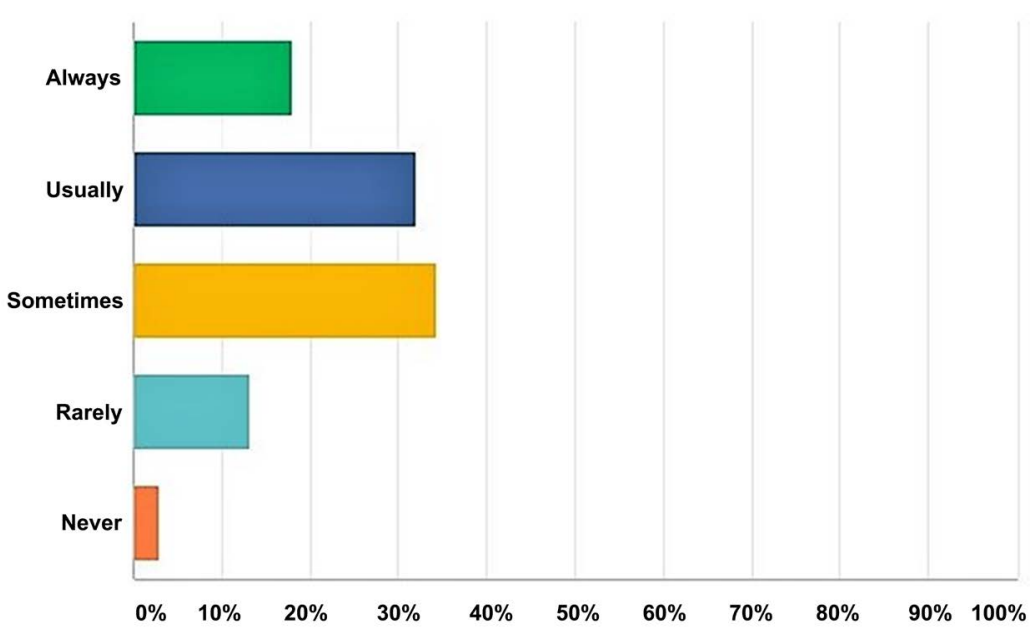

Figure 1. Summary of responses to how often do the respondents feel tempted in presence of lower price option. Source: Author's data from the quasi experiment. 
Table 2. Order of preference for menus.

\begin{tabular}{ccccccc}
\hline \multirow{2}{*}{ Menu } & \multicolumn{3}{c}{ Ice cream } & \multicolumn{3}{c}{ Shirt } \\
\cline { 2 - 6 } & $\begin{array}{c}\text { First } \\
\text { preference }\end{array}$ & $\begin{array}{c}\text { Second } \\
\text { preference }\end{array}$ & $\begin{array}{c}\text { Third } \\
\text { preference }\end{array}$ & $\begin{array}{c}\text { First } \\
\text { preference }\end{array}$ & $\begin{array}{c}\text { Second } \\
\text { preference }\end{array}$ & $\begin{array}{c}\text { Third } \\
\text { preference }\end{array}$ \\
\hline$P$ & $44.57 \%$ & $28.26 \%$ & $27.17 \%$ & $43.21 \%$ & $18.57 \%$ & $38.21 \%$ \\
$Q$ & 123 & 78 & 75 & 121 & 52 & 107 \\
& $40.94 \%$ & $49.64 \%$ & $9.42 \%$ & $31.43 \%$ & $60.36 \%$ & $8.21 \%$ \\
$R$ & 113 & 137 & 26 & 88 & 169 & 23 \\
& $14.49 \%$ & $22.10 \%$ & $63.41 \%$ & $25.36 \%$ & $21.07 \%$ & $53.57 \%$ \\
\hline
\end{tabular}

The percentage and absolute number of respondents who indicated Menus $P, Q$, and $\mathrm{R}$ as their 1 st, 2nd or 3rd preference are provided above, against Ice cream and Shirt. The total number of respondents for ice cream and shirt were 276 and 280 , respectively.

Moreover, in response to our question of choosing between alternatives $x$ and $y$ (also called Stores $X$ and $Y$ ), the responses are tabulated in Table 3 which demonstrates prevalence of temptation among them. The prevalence of different paired choices of menus, both in absolute number and in percentage terms, are tabulated in Table 4.

Not all the paired choices are internally consistent as demonstrated in Table 1. We find that for ice cream, $92.00 \%$ of the responses are internally consistent and for shirt, the corresponding figure is $89.60 \%$. These remarkably high numbers of internally consistent responses demonstrate the rational behavior of the respondents. Furthermore, only the choice $(P, X)$ is possible from the GP agent. This is the expressed choice by the respondents. Among the internally consistent respondents, this choice is observed $35.60 \%$ and $28.80 \%$ of the time, respectively, for ice cream and shirt. On a thought experiment, if the respondents had randomly chosen a menu and an alternative, only one-sixth (16.67\%) of the times, we could have observed the GP agent's choice among them. However, we observed more than twice than that in our actual observation. This is striking evidence in favor of Set Betweenness Axiom.

\subsection{Robustness Exercise: The Wealth Effect}

We undertook a robustness exercise to control for the effect of familial wealth. We considered a sub-population of the respondents belonging to the lowest wealth bracket and calculated for them all the relevant figures discussed above. Then, we considered another sub-population of respondents belonging to all other wealth brackets and did the same exercise. Table 5 and Table 6 compare and contrast the effect of familial wealth on temptation. Table 5 calculates the proportion of GP choice for menus among the both sub-populations. Table 6 calculates the proportion of internally consistent choices for Menus and Stores for both sub-populations.

From these tables, it is evident that the difference between two groups is almost non-existent for the most cases. Only remarkable difference exists in case 
Table 3. Choice among stores.

\begin{tabular}{ccc}
\hline Store & Ice cream & Shirt \\
\hline$X$ & $61.60 \%$ & $50 \%$ \\
& 154 & 125 \\
$Y$ & $38.40 \%$ & $50 \%$ \\
& 96 & 125 \\
\hline
\end{tabular}

The percentages and the absolute numbers of respondents who indicated one among the alternatives $X$ and $Y$ as their choice, are provided above. The total number of respondents for both ice cream and shirt was 250 .

Table 4. Pairwise choice for menus and stores.

\begin{tabular}{ccccc}
\hline \multirow{2}{*}{$\begin{array}{c}\text { Menu, Stores }) \\
\text { Choice pairs }\end{array}$} & No of respondents & In percentage & No of respondents & In percentage \\
\cline { 2 - 5 }$(P, X)$ & 89 & $35.60 \%$ & 72 & $28.80 \%$ \\
$(P, Y)$ & 11 & $4.40 \%$ & 12 & $4.80 \%$ \\
$(Q, X)$ & 56 & $22.40 \%$ & 39 & $15.61 \%$ \\
$(Q, Y)$ & 57 & $22.80 \%$ & 52 & $20.80 \%$ \\
$(R, X)$ & 9 & $3.60 \%$ & 14 & $5.60 \%$ \\
$(R, Y)$ & 28 & $11.20 \%$ & 61 & $24.40 \%$ \\
Total & 250 & & 250 & \\
\hline
\end{tabular}

The percentages and the absolute numbers of respondents who indicated one among the alternatives $X$ and $Y$ as their choice, are provided above. The total number of respondents for both ice cream and shirt was 250 .

Table 5. Familial wealth wise GP choice for menus.

\begin{tabular}{ccccc}
\hline \multirow{2}{*}{\begin{tabular}{c} 
Choice for Menu \\
\cline { 2 - 4 }
\end{tabular}} & $\begin{array}{c}\text { Less than INR 2 } \\
\text { Million }\end{array}$ & $\begin{array}{c}\text { More than INR 2 } \\
\text { Million }\end{array}$ & $\begin{array}{c}\text { Less than INR 2 } \\
\text { Million }\end{array}$ & $\begin{array}{c}\text { More than INR 2 } \\
\text { Million }\end{array}$ \\
\hline $\begin{array}{c}\text { P as the first } \\
\text { preference }\end{array}$ & $44.44 \%$ & $44.30 \%$ & $42.69 \%$ & $43.04 \%$ \\
Q as the second & 76 & 35 & 73 & 34 \\
preference & $50.29 \%$ & $45.57 \%$ & $60.23 \%$ & $59.49 \%$ \\
R as the third & 86 & 36 & 103 & 47 \\
preference & $61.40 \%$ & $64.56 \%$ & $50.88 \%$ & $56.96 \%$ \\
\hline
\end{tabular}

The percentages and the absolute numbers of respondents with Menus $P, Q$ and $R$ as their first, second and third preferences respectively, for two sub-populations divided on the basis of familial wealth. The first sub-population considers all who have a familial wealth of below INR 2 million and the other sub-population everyone else. The total number of respondents considered for the two sub-populations were 171 and 79 , respectively.

of proportion of GP choice among the consistent choices for ice cream. The sub-population with higher familial wealth was found to have more preference for commitment. The previous literature describes effect of wealth. However, 
Table 6. Pairwise choice of menus and stores for two sub-populations.

\begin{tabular}{ccccc}
\hline \multirow{2}{*}{$\begin{array}{c}\text { Menu, Stores) } \\
\text { Choice pairs }\end{array}$} & $\begin{array}{c}\text { Less than INR 2 } \\
\text { Million }\end{array}$ & $\begin{array}{c}\text { More than INR 2 } \\
\text { Million }\end{array}$ & $\begin{array}{c}\text { Less than INR 2 } \\
\text { Million }\end{array}$ & $\begin{array}{c}\text { More than INR 2 } \\
\text { Million }\end{array}$ \\
\cline { 2 - 5 } & $91.23 \%$ & $93.67 \%$ & $90.64 \%$ & $87.34 \%$ \\
$\begin{array}{c}\text { Internally consistent } \\
\text { choices }\end{array}$ & 156 & 74 & 155 & 69 \\
$\begin{array}{c}\text { GP choice among all } \\
\text { consistent choices }\end{array}$ & $33.33 \%$ & $43.24 \%$ & $28.65 \%$ & $29.11 \%$ \\
\hline
\end{tabular}

The percentages and the absolute numbers of respondents making an internally consistent choice and also the GP choice, for two sub-populations divided on the basis of familial wealth. The first sub-population considers all who have a familial wealth of below INR 2 million and the other sub-population everyone else. The total number of respondents considered for the two sub-populations were 171 and 79 , respectively.

since our respondents were students in their early twenties, their asset accumulation was almost negligible. Therefore, we were forced to consider familial wealth in order to allow reasonable variation in the variable concerned. We find that people from higher familial wealth background may have more preference for commitment. Therefore, familial wealth may work for a decision maker in the same manner as wealth works.

\section{Conclusions}

Economic Theory rests on assumptions which or whose implications must be testable. Set Betweenness axiom has particularly been tested in our formulation. We found that between one-third to two-fifth of the human behavior when one faced temptation, can be rationally explained by the Set Betweenness axiom. This is reasonable evidence in favor of this particular axiom.

This examination in a quasi-experimental set-up has not been attempted before. It is particularly interesting to note that we did not ask for any actual purchase decision but relied on the temptation manifested in the choice itself. The respondents are from an emerging economy unlike many previous studies. The universal nature of economic theory demand non-selective evidence which was presented here. Moreover, temptation here has been interpreted in a general manner rather than being associated with food.

Future work may explore the impact of population characteristics on the validity of the Set Betweenness axiom. Since validity of the Set Betweenness axiom means more choice is not necessarily a good option for the decision maker, the temptation assets may be encouraged so as to ensure welfare of the decision maker.

\section{References}

[1] Gul, F. and Pesendorfer, W. (2001) Temptation and Self-Control. Econometrica, 69, 1403-1435. https://doi.org/10.1111/1468-0262.00252

[2] Gul, F. and Pesendorfer, W. (2004) Self-Control, Revealed Preference and Consumption Choice. Review of Economic Dynamics, 7, 243-264.

https://doi.org/10.1016/j.red.2003.11.002 
[3] Noor, J. (2007) Commitment and Self-Control. Journal of Economic Theory, 135, 1-34. https://doi.org/10.1016/j.jet.2006.03.017

[4] Noor, J. (2011) Temptation and Revealed Preference. Econometrica, 79, 601-644. https://doi.org/10.3982/ECTA5800

[5] Milyavskaya, M. and Inzlicht, M. (2017) What's So Great about Self-Control? Examining the Importance of Effortful Self-Control and Temptation in Predicting Real-Life Depletion and Goal Attainment. Social Psychological and Personality Science, 8, 603-611. https://doi.org/10.1177/1948550616679237

[6] Hiraguchi, R. (2016) Temptation and Self-Control in a Monetary Economy. Macroeconomic Dynamics, 22, 1076-1095. https://doi.org/10.1017/S1365100516000572

[7] Woźny, Ł. (2015) On Incentives, Temptation and Self-Control. Mathematical Social Sciences, 74, 60-67. https://doi.org/10.1016/j.mathsocsci.2015.01.001

[8] Krusell, P., Kurusçu, B. and Smith, A.A. (2010) Temptation and Taxation. Econometrica, 78, 2063-2084. https://doi.org/10.3982/ECTA8611

[9] Houser, D., Schunk, D., Winter, J. and Xiao, E. (2018) Temptation and Commitment in the Laboratory. Games and Economic Behavior, 107, 329-344. https://doi.org/10.1016/j.geb.2017.10.025

[10] Hicken, A., Leider, S., Ravanilla, N. and Yang, D. (2018) Temptation in Vote-Selling: Evidence from a Field Experiment in the Philippines. Journal of Development Economics., 131, 1-14. https://doi.org/10.1016/j.jdeveco.2017.10.012

[11] Huang, K.X.D., Liu, Z. and Zhu, J.Q. (2015) Temptation and Self-Control: Some Evidence and Applications. Journal of Money, Credit and Banking, 47, 581-615,. https://doi.org/10.1111/jmcb.12222

[12] Ameriks, J., Caplin, A., Leahy, J. and Tyler, T. (2007) Measuring self-Control Problems. The American Economic Review, 97, 966-972. https://doi.org/10.1257/aer.97.3.966

[13] Vohs, K.D. and Heatherton, T.F. (2000) Self-Regulatory Failure: A Resource-Depletion Approach. Psychological Science, 11, 249-254. https://doi.org/10.1111/1467-9280.00250

[14] Twitchell, J.B. (1999) Lead Us into Temptation: The Triumph of American Materialism. Columbia University Press, New York. 